\title{
Vertical distribution and source identification of polycyclic aromatic hydrocarbons in anoxic sediment cores of Chini Lake, Malaysia: perylene as indicator of land plant- derived hydrocarbons.
}

\begin{abstract}
Four anoxic sediment cores were collected from Chini Lake, Malaysia in order to investigate the variability of polycyclic aromatic hydrocarbon $(\mathrm{PAH})$ and perylene concentrations. The study also determined significant differences of perylene concentrations in different sediment layers. Total PAH concentrations ranged from 248 to $8098 \mathrm{ng} \mathrm{g-1}$ in the samples. Diagnostic $\mathrm{PAH}$ ratios such as methylphenanthrenes/phenanthrene (MP/P), phenanthrene/anthracene (P/A) and fluoranthene/(fluoranthene + pyrene) $(\mathrm{Fl} /(\mathrm{Fl}+\mathrm{Py})$ revealed a dominance of pyrogenic influences and partial petrogenic inputs to the top sediment layers. Perylene concentrations were high in the top layers $(<12 \mathrm{~cm})$ and increased with increasing depth. There is a significant positive correlation $(\mathrm{r}=0.705, \mathrm{p}=0.01)$ between perylene concentrations and TOC. Analysis of variance (ANOVA) and LSD revealed significant differences $(\mathrm{p}<0.05)$ in TOC-normalized perylene concentrations between the upper $(<12$ $\mathrm{cm})$ and bottom layers $(>12 \mathrm{~cm})$. The average perylene concentrations accounted for $26-50 \%$ $(0-12 \mathrm{~cm})$ and $50-77 \%(12-36 \mathrm{~cm})$ of pentacyclic-aromatic hydrocarbon isomers (PAI) present whereas it made up 10-34\% $(0-12 \mathrm{~cm})$ and $46-66 \%(12-36 \mathrm{~cm})$ of the total PAH. The average pyrene concentrations decreased with increasing depth and accounted for $62 \%$ $(0-3 \mathrm{~cm}), 20-23 \%(3-12 \mathrm{~cm})$ and $3-1.4 \%(12-36 \mathrm{~cm})$ of perylene present. The results of hierarchical cluster analysis based on these ratios suggested different input sources for the top and bottom layers. It is concluded that the activity of termites on woody plants produced perylene which is supplied to the lake by run-off from the heavy and frequent rains in this Asian tropical climate. In addition, there was also in situ formation of perylene in the bottom layers due to diagenetic processes.
\end{abstract}

Keyword: - 